\title{
Solar Energy for a Solvent Recovery Stage in a Biodiesel Production Process
}

\author{
José A. León, ${ }^{1}$ Gisela Montero, ${ }^{1}$ Marcos Coronado, ${ }^{1}$ José R. Ayala, ${ }^{1}$ Conrado García, ${ }^{1}$ \\ Aníbal Luna, ${ }^{2}$ and Ana M. Vázquez ${ }^{3}$ \\ ${ }^{1}$ Engineering Institute, Universidad Autónoma de Baja California, Boulevard B. Juárez y Calle de la Normal S/N, \\ 21280 Mexicali, BCN, Mexico \\ ${ }^{2}$ Faculty of Architecture and Design, Universidad Autónoma de Baja California, Boulevard B. Juárez y Calle de la Normal S/N, \\ 21280 Mexicali, BCN, Mexico \\ ${ }^{3}$ School of Engineering and Business Guadalupe Victoria, Universidad Autónoma de Baja California, \\ Carretera Estatal No. 3 Col. Gutiérrez, 21720 Mexicali, BCN, Mexico
}

Correspondence should be addressed to Gisela Montero; gmontero@uabc.edu.mx

Received 29 March 2016; Accepted 15 June 2016

Academic Editor: Juan M. Coronado

Copyright (C) 2016 José A. León et al. This is an open access article distributed under the Creative Commons Attribution License, which permits unrestricted use, distribution, and reproduction in any medium, provided the original work is properly cited.

Recent research and development of clean energy have become essential due to the global climate change problem, which is caused largely by fossil fuels burning. Therefore, biodiesel, a renewable and ecofriendly biofuel with less environmental impact than diesel, continues expanding worldwide. The process for biodiesel production involves a significant energy demand, specifically in the methanol recovery stage through a flash separator and a distillation column. Traditionally, the energy required for this process is supplied by fossil fuels. It represents an opportunity for the application of renewable energy. Hence, the current study presents a system of thermal energy storage modeled in TRNSYS ${ }^{\circledR}$ and supported by simulations performed in ASPEN PLUS ${ }^{\circledR}$. The aim of this research was to supply solar energy for a methanol recovery stage in a biodiesel production process. The results highlighted that it is feasible to meet $91 \%$ of the energy demand with an array of 9 parabolic trough collectors. The array obtained from the simulation was 3 in series and 3 in parallel, with a total area of $118.8 \mathrm{~m}^{2}$. It represents an energy saving of $70 \mathrm{MWh}$ per year.

\section{Introduction}

The excessive use of fossil fuels for energy supply in the daily life of humanity has had significant environmental consequences. It coupled with an increasing shortage has caused the world to experience a transition from fossil fuels to some renewable energy source $[1,2]$. Solar energy has great potential as renewable energy due to its abundance, and its use has been growing more every year, from heating water for households to power generation [3-5].

Solar energy in industry swaps the massive consumption of commercially available electricity. Some industrial pro-cesses such as drying, sterilization, cooking, cleaning or degreasing, and pasteurization require heat energy. All the processes temperature required is less than $260^{\circ} \mathrm{C}$ [6]. Other applications as cleaning, evaporation, distillation, and cooking, among others, as well as applications with low-temperature heat demand and high consumption rates (domestic hot water, space heating, and swimming pool heating), and heat-driven refrigeration and cooling require temperatures between 85 and $250^{\circ} \mathrm{C}$. Recently, one of the aims of solar-thermal engineering is to enhance parabolic trough concentrators for industrial processes. Some research reported in the literature is addressed to the development of new devices, new applications, control methodologies, thermodynamic and technical-economic analysis, and the development of components, support structures, reflective materials, materials for the receiver, and absorber surfaces [7]. One kind of parabolic trough concentrator (PTC) is destined to provide heat to processes that need temperatures between 100 and $250^{\circ} \mathrm{C}$. The typical aperture widths are between 1 and $3 \mathrm{~m}$; total lengths vary between 2 and $10 \mathrm{~m}$ by row, and geometrical concentrating ratios are between 15 and 20. The PTC of this group are called "medium temperature collectors" 


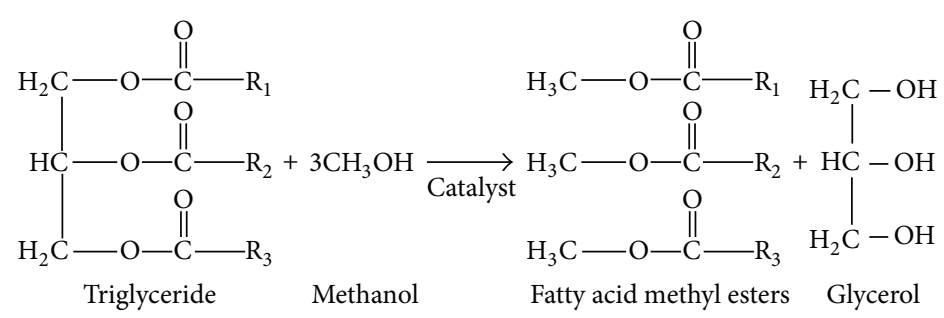

FIGURE 1: Transesterification reaction to obtain biodiesel.

[8]. Some of the applications of PTC face space constraints on the solar field. Factories today are usually located in industrial areas where land is often limited and expensive, so installing the solar field on roofs should be a real possibility [9]. Solar energy is being used for industrial processes in various developing countries. According to International Energy Agency (IEA) currently 120 operating solar-thermal systems for process heat are reported worldwide, with a total capacity of about $88 \mathrm{MW}\left(125,000 \mathrm{~m}^{2}\right)$ [6].

Recently, biodiesel has become more attractive because of its environmental benefits and by the fact that it is produced from biomass, a renewable resource $[10,11]$. However, the production cost of biodiesel is the main obstacle for the marketing of the product $[12,13]$. The biodiesel production process involves a significant energy demand, specifically in the methanol recovery stage through a flash separator and a distillation column. Traditionally, the energy required is supplied by fossil fuels. It represents an opportunity for the application of renewable energy. Hence, the current study presents a system of thermal energy storage modeled in TRNSYS and supported by simulations performed in ASPEN PLUS. The aim of this research was to supply solar energy for a methanol recovery stage in a biodiesel production process in Mexicali, Baja California, Mexico.

Previous work performed simulations using ASPEN PLUS, generating steam and power with solar collectors and photovoltaic panels applied to biodiesel production process [14]. However, important parameters concerning the use of solar collectors, for example, the variation in solar irradiation, the type of solar collector, orientation and inclination, and arrangement of the storage system, were not considered. In the present work, these parameters were included by the utilization of a dynamic simulator called TRNSYS.

ASPEN PLUS is a process modeling software suitable for a variety of steady-state modeling applications. The ASPEN system is based on "blocks" corresponding to unit operations as well as chemical reactors, through which most industrial operations can be simulated [15]. ASPEN PLUS is widely used for simulation processes in different industries, for example, oil and gas, chemical, engineering and construction, pharmaceutical, food, and beverage $[16,17]$.

TRNSYS is an acronym for a "transient simulation" which is a quasi-steady simulation model. This program was developed by the University of Wisconsin by the members of the Solar Energy Laboratory [18]. It has been used in the evaluation of solar technologies, including their different design parameters and operating conditions for a specific location in order to obtain reliable results [19-22].

Castor oil was the feedstock used for biodiesel production in the simulation. It consists of triglycerides comprised by $90 \%$ of ricinoleic acid [23]. Therefore, the triricinolein was considered as the representative castor oil molecule in the present simulation. Methyl ricinoleate is the corresponding ester of ricinoleic acid and the primary product of the transesterification reaction, which represents the biodiesel. The byproduct of this reaction is glycerol. The transesterification reaction is catalyzed by sodium hydroxide, and the product mixture is neutralized with sulfuric acid. This reaction is shown in Figure 1 [10].

The production process of biodiesel from castor oil in ASPEN PLUS consists of 5 stages: pretreatment, transesterification, separation, neutralization, and alcohol recovery $[24,25]$.

A biodiesel production plant was simulated in ASPEN PLUS, and it was designed to maintain a biodiesel production of $83.3 \mathrm{~kg} / \mathrm{h}$. To achieve it, it is necessary to supply $10.63 \mathrm{~kW}$ to the process, where $82.6 \%$ of that power is used for the methanol recovery. The flash separator and the reboiler of methanol recovery column consume $2.76 \mathrm{~kW}$ and $6.02 \mathrm{~kW}$, respectively. The complete process diagram developed in ASPEN PLUS can be seen in Figure 2.

The solar irradiation in Mexicali, Baja California, was used for heating the heat transfer fluid (HTF) in heat exchangers in the biodiesel production process, specifically, the methanol recovery stage. As a result, the fossil fuels consumption is reduced by the utilization of solar energy. The implementation of solar collector technologies in existing processes represents an opportunity at an industrial level, as it may reduce operation costs associated with heating streams.

\section{Methodology}

2.1. Study Area. Mexico is located between $14^{\circ}$ and $33^{\circ} \mathrm{N}$, a region ideal for the solar energy exploitation. The average daily global irradiation in the country is about $5.5 \mathrm{kWh} / \mathrm{m}^{2}$ [26]. Mexicali, a northwest city of Mexico, is located on the border with the State of California, USA, and has an average daily normal irradiation (ADNI) on June about $10 \mathrm{kWh} / \mathrm{m}^{2}$. Analysis of power generation by the solar irradiation database of the National Renewable Energy Laboratory (NREL) establishes that Mexicali has ADNI levels above $6.5 \mathrm{~kW} / \mathrm{m}^{2} /$ day. According to NREL, a site with an ADNI level greater than 


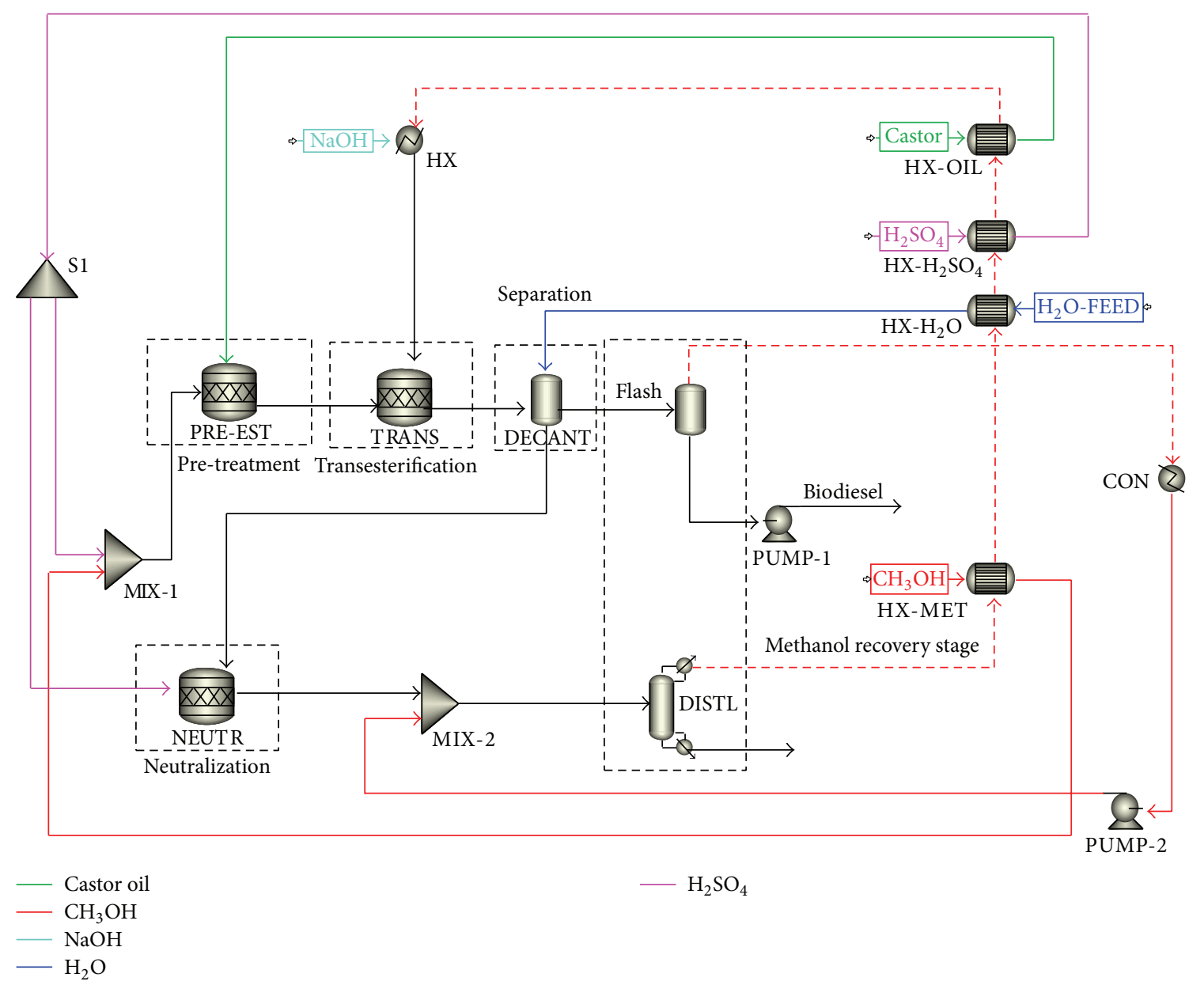

FIGURE 2: Diagram of biodiesel production process in ASPEN PLUS.

$6 \mathrm{kWh} / \mathrm{m}^{2} /$ day, it is considered a profitable area for the exploitation of solar resource [27].

In general, the long-term performance prediction of any solar energy system depends on the long-term climatic features of the location where it is to be used. The need for using a one-year meteorological data file to evaluate the long-term system performance has led to the development of the typical meteorological year (TMY). The TMY is a set of hourly values of solar irradiation and meteorological elements for one year generated from observed long-term data [28].

The TMY file information considered for Mexicali in the simulation was a ten-year average from 2000 to 2009 obtained from the METEONORM ${ }^{\circledR}$ software database [29].

2.2. General Methodology Description. Figure 3 displays the methodology scheme applied for the development of this work, where the interaction between the user and the simulation software is highlighted.

First, an HTF able to work over a wide range of temperatures was selected and uploaded to ASPEN PLUS. The transfer of energy from the HTF to the flash and the reboiler was represented through a heat exchanger for each equipment. Based on the simulation, the stream values of the HTF such as temperature and mass flow suitable to convey the energy required by the process were determined.

Once the HTF stream values and properties required were estimated, the thermal storage system was dimensioned. The info on the sizes of tanks and HTF stream and its properties were provided to TRNSYS.

Through TRNSYS, the final solar collector's array that can provide the energy required for the solvent recovery stage in the biodiesel process, with the lower auxiliary power consumption, was obtained. TRNSYS simulation was dynamic and allowed evaluating the behavior of the system during an average year of continuous operation.

2.3. Thermal Energy Storage System. The energy needed for the continuous operation of the biodiesel process was carried out through solar heating of the HTF. The energy storage system includes a tank for the fluid, prior heating $(\operatorname{tank} 1)$, and another tank for the heated fluid (tank 2). Also, an array of solar collectors and two heat exchangers are included, which represent the methanol recovery stage where the thermal energy is supplied.

The HTF selected was ethylene glycol, antifreeze used in various applications due to its wide range of working temperatures [30]. 


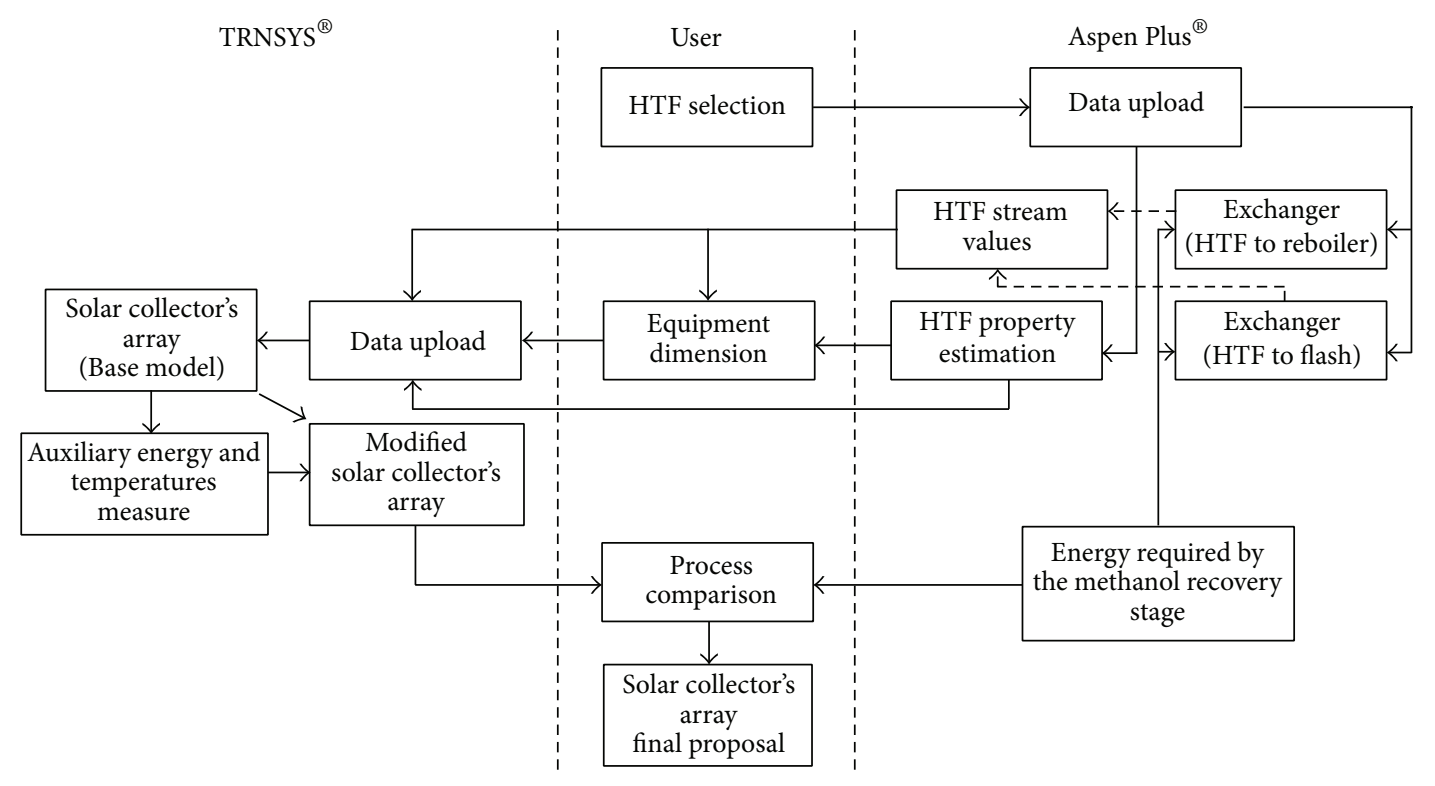

FIgURE 3: Methodology scheme applied.

The working temperature, the heat transfer coefficients, and the mass flows of the HTF were estimated in ASPEN PLUS.

The shortcut method was used for the heat exchangers calculation, specifying the outlet temperature and pressure of the stream that receives energy. The outlet temperature and pressure for the flash separator were $110^{\circ} \mathrm{C}$ and $10.1 \mathrm{kPa}$, while being $93^{\circ} \mathrm{C}$ and $110 \mathrm{kPa}$ for the reboiler. The flow arrangement of the heat exchangers was defined as countercurrent and the correction factor $(F)$ method for the logarithmic mean temperature difference (LMTD) was stated constantly. The overall heat transfer coefficients $(U)$ were $850 \mathrm{~W} / \mathrm{m}^{2} \mathrm{~K}$.

The storage tanks volumes and their inlet and outlet flows were calculated based on the density of the HTF. Two arrays of solar technologies were evaluated: evacuated tube collectors (ETC) and parabolic trough collectors (PTC).

\section{Results and Discussion}

According to the results obtained in ASPEN PLUS, the working temperature of HTF to deliver the heat required was $120^{\circ} \mathrm{C}$. The heat transfer coefficient $(U A)$ and the area $(A)$ of the column reboiler were $482.31 \mathrm{~W} / \mathrm{K}$ and $0.57 \mathrm{~m}^{2}$, while being $394.82 \mathrm{~W} / \mathrm{K}$ and $0.46 \mathrm{~m}^{2}$ for the flash separator. The mass flows for the column reboiler and flash separator were $270 \mathrm{~kg} / \mathrm{h}$ and $93 \mathrm{~kg} / \mathrm{h}$, respectively.

The volume required for tank 1 was $9 \mathrm{~m}^{3}$ while for tank 2 it was $7 \mathrm{~m}^{3}$. The HTF mass outflows were $1,452 \mathrm{~kg} / \mathrm{h}$ for tank 1 and $363 \mathrm{~kg} / \mathrm{h}$ for tank 2 . The difference between outflows is because the HTF must be heated when solar irradiation is available.

With the purpose of heating the HTF and maintaining it at $120^{\circ} \mathrm{C}$, ETC were analyzed. The tilt and azimuth angle of the ETC evaluated were $32^{\circ}$ and $0^{\circ}$, respectively. The solar collectors array does not have a sun tracking system. The

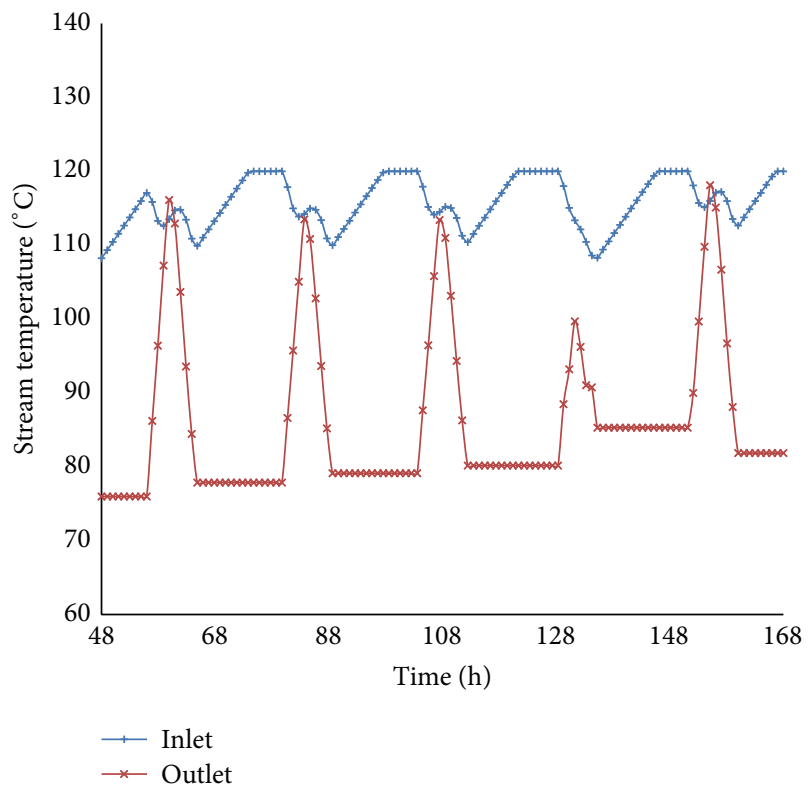

FIgURE 4: Variation of the temperature at the inlet and outlet of the tank 2 for the array with evacuated tube collectors.

array of the collectors was 3 in series and 30 in parallel with an individual area of $2.89 \mathrm{~m}^{2}$.

The temperature behavior at the inlet and outlet of the tank 2 is illustrated in Figure 4.

The large variation of the output temperature is observed because the solar collectors hardly reach a temperature of $120^{\circ} \mathrm{C}$. With this variation, it is necessary to activate the auxiliary heating in tank 2 frequently, which represents an annual energy consumption of $18.9 \mathrm{MWh}$.

To achieve an HTF temperature above $120^{\circ} \mathrm{C}$, parabolic trough collectors (PTC) were also analyzed. The PTC are 


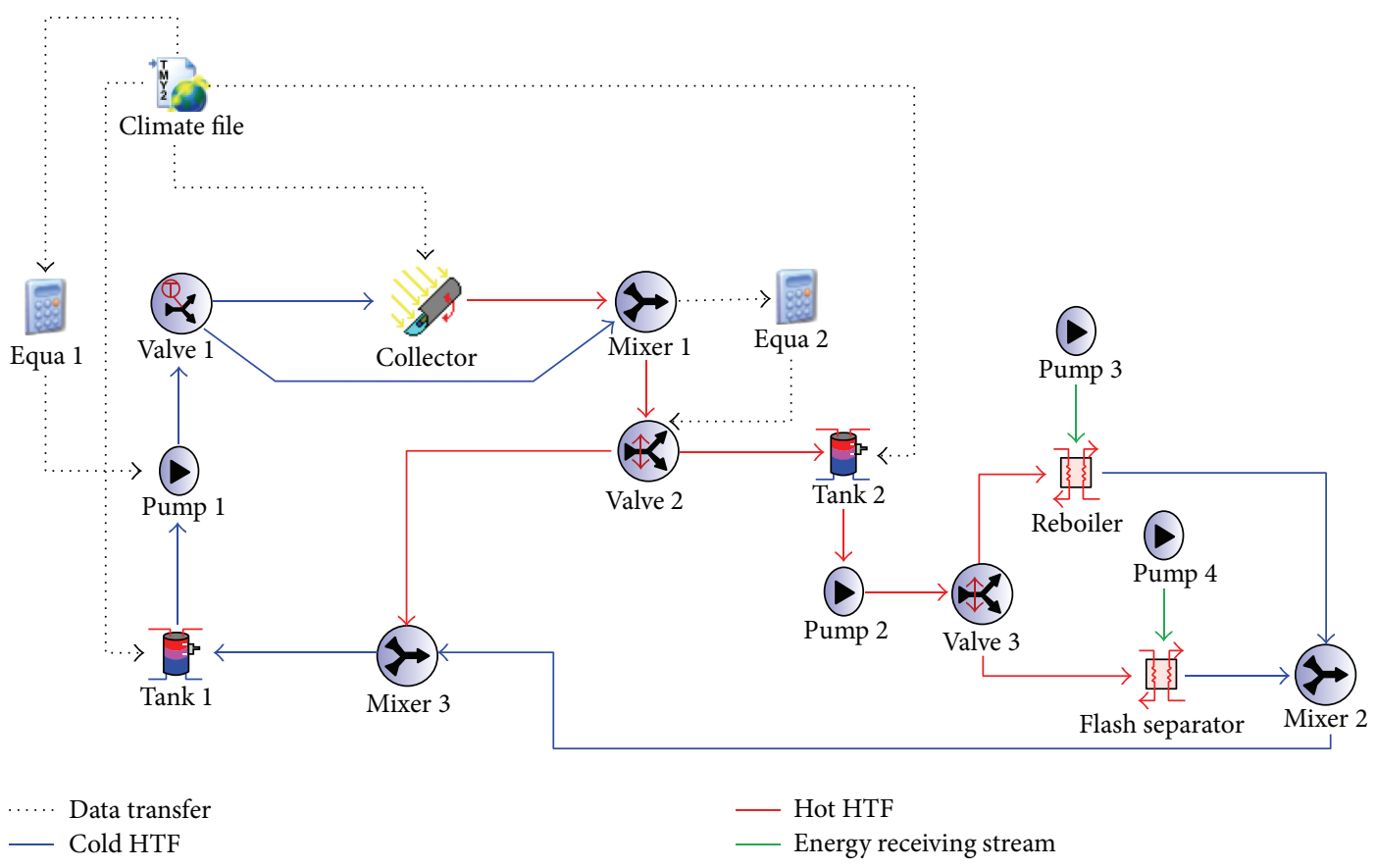

FIGURE 5: TRNSYS simulation diagram for parabolic trough collectors.

more expensive in small scale applications than the ETC, but the PTC efficiency is higher than the ETC [31]. The PTC have been used in power generation due to high temperatures that can be reached $[32,33]$. According to the literature, the costs of medium temperature solar collectors range between $\$ 195 / \mathrm{m}^{2}$ and $\$ 390 / \mathrm{m}^{2}$ [34]. The research and development of this kind of technology will allow a reduction of the cost of the construction of medium temperature solar collectors. Recent investigations have reported experimental PTC prototypes with a manufacturing cost of $\$ 170 / \mathrm{m}^{2}[35]$ and even $\$ 58.5 / \mathrm{m}^{2}$ [36].

New designs are being studied which reduce the cost of PTC [37].

The arrangement of PTC was comprised by 3 collectors in series and 3 in parallel with an individual area of $13.2 \mathrm{~m}^{2}$. The collectors were enabled with a single axis tracking and fixed azimuth orientation to the south. PTC reach temperatures above $120^{\circ} \mathrm{C}$ allowing controlling the outlet temperature of tank 2.

The heating process diagram for PTC developed in TRNSYS is displayed in Figure 5. The following conditions in the simulation to maintain a constant flow of HTF at $120^{\circ} \mathrm{C}$ were taken:

(i) The pump 1 controls the outlet flow of the tank 1 . The Equa 1 module receives information about the level of solar irradiation from the climate file and then, it sends a control signal to drive the pump 1 . This pump will only be activated when the solar irradiation is above $270 \mathrm{~W} / \mathrm{m}^{2}$. The solar irradiation value was determined in a preliminary analysis.

(ii) The valve 1 regulates the flow to the solar collectors and the mixer 1 , by measuring the temperature at the outlet of the collectors. When the temperature in the outlet flow of the collectors is greater than $120^{\circ} \mathrm{C}$, the valve 1 divides the HTF flow, to keep the temperature at $120^{\circ} \mathrm{C}$ in the outlet flow of the mixer 1.

(iii) The valve 2 sends the HTF to tank 2 and is controlled by the Equa 2 module. The module Equa 2 measures the temperature at the outlet of the mixer 1 . If the temperature equals or exceeds $120^{\circ} \mathrm{C}$, Equa 2 sends the signal to drive the valve 2 and the HTF is sent to the tank 2. Otherwise, all the HTF is directed to the mixer 3. As a result, less variation of temperature occurs in the outlet of $\operatorname{tank} 2$.

The monthly energy required in the process, the energy consumed by the auxiliary heating in tank 2 , and the monthly energy savings using PTC are observed in Figure 6.

The utilization of PTC permits a minimal use of auxiliary energy in tank 2, particularly in summer. It represents an annual electrical saving of $70 \mathrm{MWh}$ and a natural gas reduction of $14,232 \mathrm{~m}^{3}$, based on a combined cycle power generation plant in Mexicali with an efficiency of 50\%. Environmentally, $27.3 \mathrm{t}$ of $\mathrm{CO}_{2}$ emissions could be reduced per year approximately.

\section{Conclusions}

The biodiesel process presented in this work required a constant supply of thermal energy at temperatures between $60^{\circ} \mathrm{C}$ and $120^{\circ} \mathrm{C}$. The medium temperatures solar collectors are one of the best technological options for this application. Even though the solar energy could be applied to the transesterification reactor, the aim of this investigation was to supply energy to the process stage that demands the greater thermal 


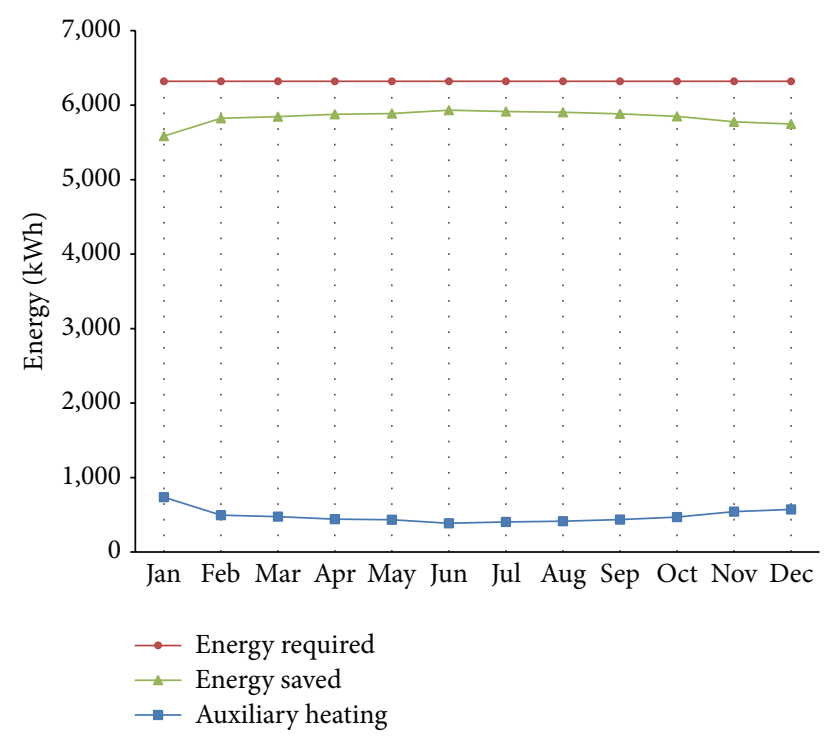

FIgURE 6: Comparison of energy required.

load. Further investigations will be conducted to provide energy to the overall process. The parabolic trough collectors array turned out to be the best option over the evacuated tube collectors to supply the power required for the solvent recovery stage in a biodiesel production process. It is because the PTC efficiency is higher than the ETC. For a constant thermal energy supply, only the PTC can easily increase the HTF temperature above $120^{\circ} \mathrm{C}$. The PTC could be more expensive in a small-scale power generation installed capacity. For industrial applications, PTC have smaller dimensions, due to the lowest temperatures required, which imply lower manufacture, installation, and maintenance cost. The final array for supplying the heat required in the methanol recovery stage is comprised of 9 parabolic trough collectors, 3 in series and 3 in parallel with a total collection area of $118.8 \mathrm{~m}^{2}$. The collectors were enabled with a single axis tracking and fixed azimuth orientation to the south. This system provides $91 \%$ of the energy demanded by the methanol recovery stage in the biodiesel production process. According to the high solar irradiation in the area, Mexicali has great potential for the application of solar energy in industrial processes. The use of solar energy through the thermal energy storage systems allows power savings and reducing greenhouse gasses emissions by avoiding the burning of fossil fuels.

\section{Competing Interests}

The authors declare that there is no conflict of interests regarding the publication of this paper.

\section{Acknowledgments}

The authors thank the Engineering Institute of Universidad Autónoma de Baja California, for the facilities to develop this project, and CONACYT for the financial support for the publication of this paper.

\section{References}

[1] N. Armaroli and V. Balzani, "The future of energy supply: challenges and opportunities," Angewandte Chemie-International Edition, vol. 46, no. 1-2, pp. 52-66, 2007.

[2] G. Montero, M. Stoytcheva, M. Coronado et al., "An overview of biodiesel production in Mexico," in Biofuels-Status and Perspective, K. Biernat, Ed., chapter 19, InTech, Rijeka, Croatia, 2015.

[3] S. A. Kalogirou, "Solar thermal collectors and applications," Progress in Energy and Combustion Science, vol. 30, no. 3, pp. 231295, 2004.

[4] H. Kim, E. Park, S. J. Kwon, J. Y. Ohm, and H. J. Chang, "An integrated adoption model of solar energy technologies in South Korea," Renewable Energy, vol. 66, pp. 523-531, 2014.

[5] E. Sanz-Casado, M. L. Lascurain-Sánchez, A. E. Serrano-Lopez, B. Larsen, and P. Ingwersen, "Production, consumption and research on solar energy: the Spanish and German case," Renewable Energy, vol. 68, pp. 733-744, 2014.

[6] V. K. Jebasingh and G. M. J. Herbert, "A review of solar parabolic trough collector," Renewable and Sustainable Energy Reviews, vol. 54, pp. 1085-1091, 2016.

[7] O. A. Jaramillo, M. Borunda, K. M. Velazquez-Lucho, and M. Robles, "Parabolic trough solar collector for low enthalpy processes: an analysis of the efficiency enhancement by using twisted tape inserts," Renewable Energy, vol. 93, pp. 125-141, 2016.

[8] M. Balghouthi, A. B. Hadj Ali, S. E. Trabelsi, and A. Guizani, "Optical and thermal evaluations of a medium temperature parabolic trough solar collector used in a cooling installation," Energy Conversion and Management, vol. 86, pp. 1134-1146, 2014.

[9] A. Fernández-García, E. Rojas, M. Pérez, R. Silva, Q. Hernández-Escobedo, and F. Manzano-Agugliaro, "A parabolic-trough collector for cleaner industrial process heat," Journal of Cleaner Production, vol. 89, pp. 272-285, 2015.

[10] M. Coronado, G. Montero, B. Valdez et al., "Degradation of nitrile rubber fuel hose by biodiesel use," Energy, vol. 68, pp. 364-369, 2014.

[11] P. Collet, L. Lardon, A. Hélias et al., "Biodiesel from microalgae-life cycle assessment and recommendations for potential improvements," Renewable Energy, vol. 71, pp. 525-533, 2014.

[12] F. Ma and M. A. Hanna, "Biodiesel production: a review," Bioresource Technology, vol. 70, no. 1, pp. 1-15, 1999.

[13] H. Chen and G. Q. Chen, "Energy cost of rapeseed-based biodiesel as alternative energy in China," Renewable Energy, vol. 36, no. 5, pp. 1374-1378, 2011.

[14] Z. Hou and D. Zheng, "Solar utility and renewability evaluation for biodiesel production process," Applied Thermal Engineering, vol. 29, no. 14-15, pp. 3169-3174, 2009.

[15] L. Zheng and E. Furimsky, "ASPEN simulation of cogeneration plants," Energy Conversion and Management, vol. 44, no. 11, pp. 1845-1851, 2003.

[16] Aspen Plus software, Aspen Tech, https://www.aspentech.com/.

[17] G. Song, F. Feng, J. Xiao, and L. Shen, “Technical assessment of synthetic natural gas (SNG) production from agriculture residuals," Journal of Thermal Science, vol. 22, no. 4, pp. 359-365, 2013.

[18] Solar Energy Laboratory, TRNSYS Program Manual, Solar Energy Laboratory, University of Wisconsin-Madison, Madison, Wis, USA, 1996, http://www.trnsys.com/. 
[19] W. A. Beckman, L. Broman, A. Fiksel et al., "TRNSYS the most complete solar energy system modeling and simulation software," Renewable Energy, vol. 5, no. 1-4, pp. 486-488, 1994.

[20] S. Sinha and S. S. Chandel, "Review of software tools for hybrid renewable energy systems," Renewable and Sustainable Energy Reviews, vol. 32, pp. 192-205, 2014.

[21] M. M. S. Dezfouli, S. Mat, G. Pirasteh, K. S. M. Sahari, K. Sopian, and M. H. Ruslan, "Simulation analysis of the four configurations of solar desiccant cooling system using evaporative cooling in tropical weather in Malaysia," International Journal of Photoenergy, vol. 2014, Article ID 843617, 14 pages, 2014.

[22] X. Ji, M. Li, W. Lin, T. Zheng, and Y. Wang, "Effect of installation of solar collector on performance of balcony split type solar water heaters," International Journal of Photoenergy, vol. 2015, Article ID 865041, 9 pages, 2015.

[23] M. M. Conceição, R. A. Candeia, F. C. Silva, A. F. Bezerra, V. J. Fernandes Jr., and A. G. Souza, "Thermoanalytical characterization of castor oil biodiesel," Renewable and Sustainable Energy Reviews, vol. 11, no. 5, pp. 964-975, 2007.

[24] J. Cerezo, G. Montero, I. Aguilar, R. Romero, and H. Campbell, "Energetic and exergetic analysis for obtaining biodiesel from higuerilla," in Proceedings of the 8th Conference on Sustainable Development of Energy, Water and Environment Systems, Dubrovnik, Croatia, September 2013.

[25] G. Montero, M. Stoytcheva, C. García et al., "Current status of biodiesel production in Baja California, Mexico," in Biodiesel: Quality, Emissions and by-Products, M. Gisela, Ed., pp. 137-152, InTech, Rijeka, Croatia, 2011.

[26] Secretaría De Energía, Prospectiva de Energías Renovables 20132027, Secretaría De Energía, México, D.F., Mexico, 2013.

[27] V. López, "La energía solar como promotora del desarollo regional: análisis del potencial de generación en Baja California," Revista Internacional Administración \& Finanzas (RIAF), vol. 5, no. 1, pp. 53-64, 2012.

[28] T. Lhendup and S. Lhundup, "Comparison of methodologies for generating a typical meteorological year (TMY)," Energy for Sustainable Development, vol. 11, no. 3, pp. 5-10, 2007.

[29] Meteonorm Software, Meteotest 2015, http://www.meteonorm .com/.

[30] V. Trisaksri and S. Wongwises, "Critical review of heat transfer characteristics of nanofluids," Renewable and Sustainable Energy Reviews, vol. 11, no. 3, pp. 512-523, 2007.

[31] E. M. A. Mokheimer, Y. N. Dabwan, M. A. Habib, S. A. M. Said, and F. A. Al-Sulaiman, "Techno-economic performance analysis of parabolic trough collector in Dhahran, Saudi Arabia," Energy Conversion and Management, vol. 86, pp. 622-633, 2014.

[32] S. Kuravi, J. Trahan, D. Yogi Goswami, M. M. Rahman, and E. K. Stefanakos, "Thermal energy storage technologies and systems for concentrating solar power plants," Progress in Energy and Combustion Science, vol. 39, no. 4, pp. 285-319, 2013.

[33] A. Fernández-García, E. Zarza, L. Valenzuela, and M. Pérez, "Parabolic-trough solar collectors and their applications," Renewable and Sustainable Energy Reviews, vol. 14, no. 7, pp. 1695-1721, 2010.

[34] W. Weiss and M. Rommel, "Solar heat for industrial processes, medium temperature collectors," State of the Art within Task 33/IV, Subtask C. Solar Heating and Cooling Executive Committee of the International Energy Agency, 2005.

[35] O. A. Jaramillo, E. Venegas-Reyes, J. O. Aguilar, R. CastrejónGarcía, and F. Sosa-Montemayor, "Parabolic trough concentrators for low enthalpy processes," Renewable Energy, vol. 60, pp. 529-539, 2013.
[36] F. M. I. De Los Santos-García, Y. Nahmad-Molinari, J. NietoNavarro, C. Alanís-Ruiz, and F. Patiño-Jiménez, "Construction and testing of lightweight and low-cost pneumatically inflated solar concentrators," International Journal of Photoenergy, vol. 2016, Article ID 2758546, 8 pages, 2016.

[37] G. Coccia, G. Di Nicola, and M. Sotte, "Design, manufacture, and test of a prototype for a parabolic trough collector for industrial process heat," Renewable Energy, vol. 74, pp. 727-736, 2015. 

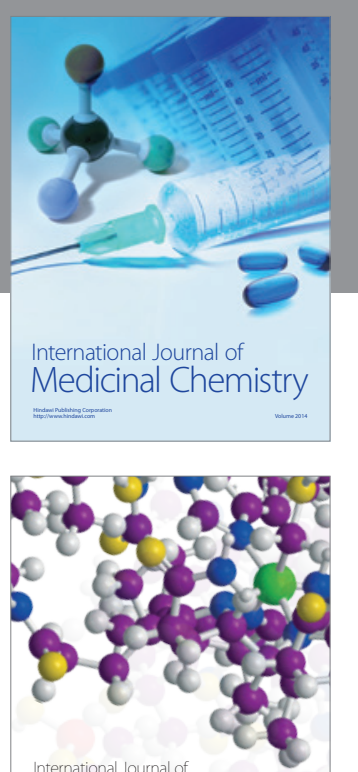

Carbohydrate Chemistry

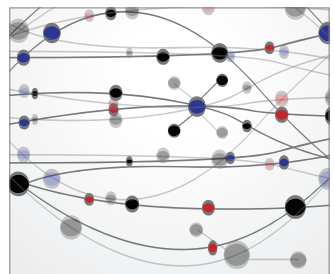

The Scientific World Journal
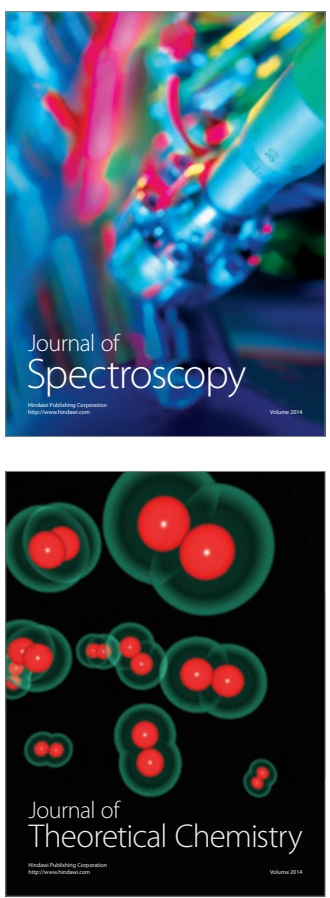
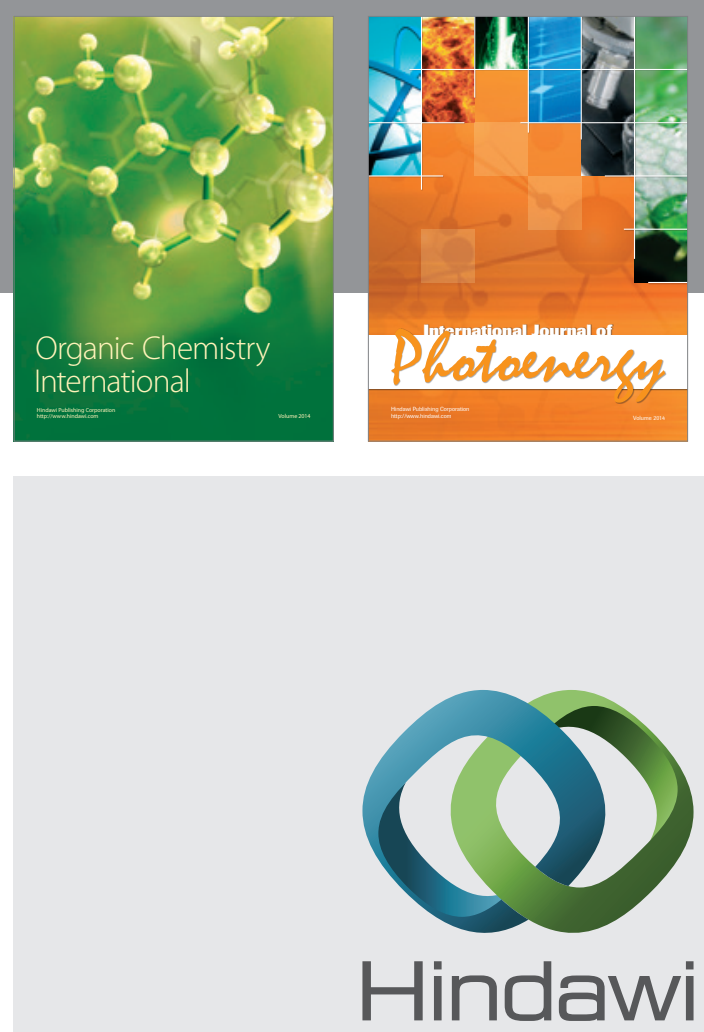

Submit your manuscripts at

http://www.hindawi.com

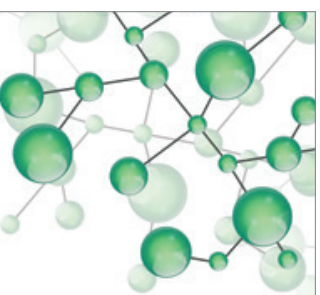

International Journal of

Inorganic Chemistry

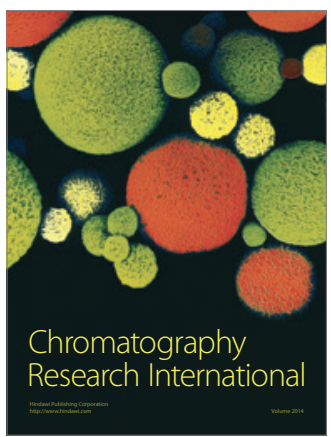

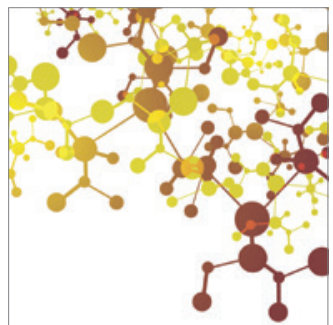

Applied Chemistry
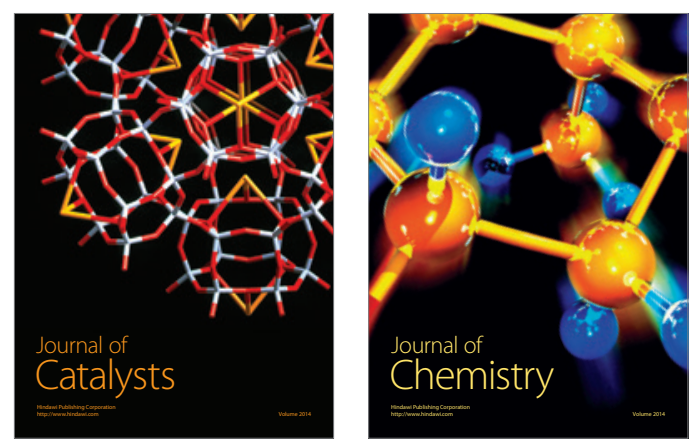
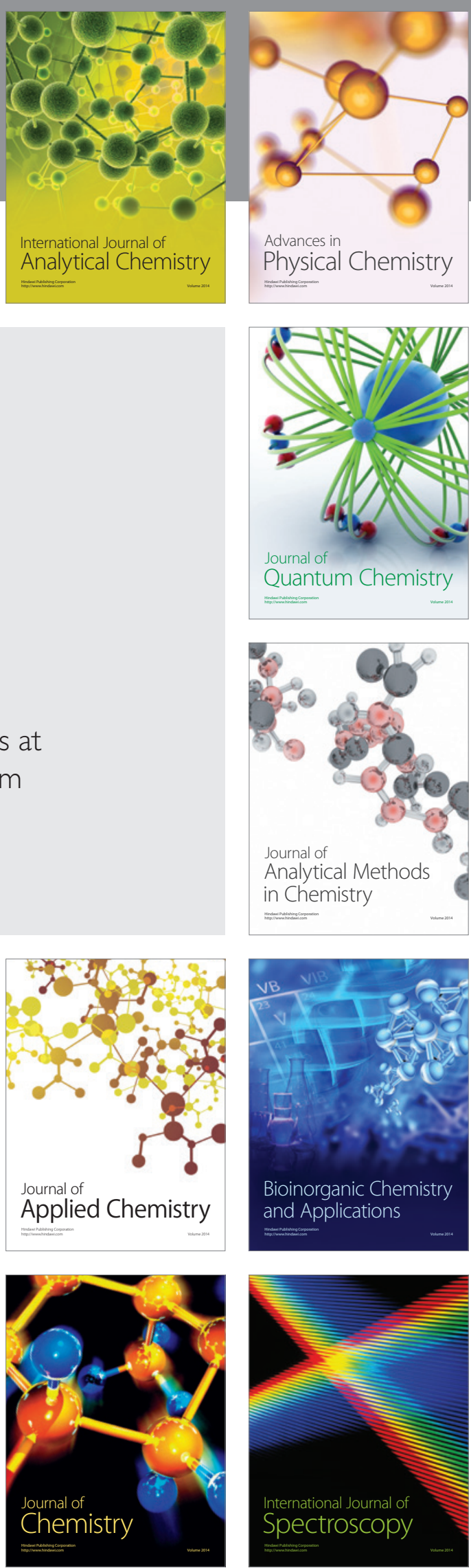